\title{
Cenários prospectivos da produção e armazenagem de grãos no Brasil
}

\author{
Prospective scenarios of grain production and storage in Brazil
}

Gabriel Debarba Baroni ${ }^{1}$; Pedro Henrique Benedetii; Denílson José Seidel ${ }^{1}$

\section{RESUMO}

Com o aumento da população mundial e, consequentemente, da demanda por alimento, o tema produção e armazenamento de grãos se faz relevante, tanto em nível nacional como internacional. Sabe-se que o Brasil é um dos maiores produtores de grãos do mundo, devido, principalmente, a sua grande extensão territorial, clima favorável e utilização de tecnologia para manejo da lavoura. Mas, além de produzir, é de fundamental importância efetuar o armazenamento correto para conseguir minimizar as perdas de grãos, juntamente com prejuízos financeiros e logísticos. Atualmente, a produção de grãos vem aumentando em grandes proporções se comparado com a capacidade estática, por diversos fatores. Por isso, neste artigo realizou-se uma estimativa da produção e armazenagem de grãos do Brasil, tendo como base os dados fornecidos pela Companhia Nacional de Abastecimento (CONAB) e usando o Método dos Mínimos Quadrados. A partir disso, é possível demonstrar para investidores as áreas geográficas onde a busca por capacidade estática será maior e consequentemente o negócio seja mais rentável e atrativo.

Palavras-chave: Déficit de armazenagem; Grãos; Método dos Mínimos Quadrados; Produção.

\begin{abstract}
With the increase in the world population and, consequently, the demand for food, the issue of grain production and storage becomes relevant, both at the national and international levels. It is known that Brazil is one of the largest grain producers in the world, due to, mainly, its great territorial extension, favorable climate and use of technology for crop management. But, besides producing, it is crucial to make the correct storage to be able to minimize grain losses, along with financial and logistical damages. Currently, grain production has increased in large proportions compared to static capacity, due to several factors. Therefore, in this article an estimation of grain production and storage in Brazil was carried out, based on the data provided by the National Supply Company (CONAB) and using the Least Square Method. From this, it is possible to demonstrate to do investors the geographical areas where the search for static capacity will be larger and consequently the business will be more profitable and attractive.
\end{abstract}

Keywords: Deficit of storage; Grains; Minimum Squares Method; Production.

\footnotetext{
${ }^{1}$ IFSul - Instituto Federal de Educação, Ciência e Tecnologia Sul-rio-grandense, Passo Fundo/RS - Brasil.
} 


\section{INTRODUÇÃO}

As modificações advindas do processo de modernização da agricultura no Brasil ao longo das últimas décadas têm levado ao aumento da produção de alimentos, principalmente alguns tipos de grãos como o milho, o trigo, a soja e a cevada. Conforme dados divulgados pela Empresa Brasileira de Pesquisa Agropecuária (EMBRAPA, 2017), que dizem respeito a produção de soja, nosso país é o segundo maior produtor desse grão, perdendo apenas para os Estados Unidos.

Aliado ao acréscimo na produção, há também a demanda por locais adequados para que se possam armazenar esses produtos por um período de tempo maior e conservar as propriedades dos grãos colhidos, uma vez que além de produzir, é preciso armazenar os produtos com eficiência, a fim de preservar a qualidade e as características primárias, para que se possa garantir o menor desperdício possível dos mesmos.

No entanto, apesar dessa produção estar crescendo expressivamente, sua capacidade de armazenagem não cresce no mesmo ritmo. Isso faz com que os produtores não possam armazenar seus grãos para a venda na entressafra, onde o preço sofre um aumento, fazendo assim, com que o produtor obtenha menor lucro tendo que vender o grão durante a safra.

Devido a esse crescimento desequilibrado da produção em relação a armazenagem, a finalidade deste trabalho é analisar os dados existentes da quantidade de produção de grãos e da capacidade de armazenagem para estes, e assim, realizar uma estimativa sobre esses aspectos para os próximos anos, via Método dos Mínimos Quadrados². Esses dados foram coletados no ano de 2017, junto à Companhia Nacional de Abastecimento (CONAB), - uma empresa pública que executa estudos e estatísticas, de expectativas de produção de grãos, volume e localização dos armazéns públicos e privados. Os tipos de grãos contabilizados pela CONAB (2017) são: caroço de algodão, amendoim, arroz, aveia, centeio, cevada, feijão, girassol, mamona, milho, soja, sorgo, trigo e triticale. Além disso, este estudo fornecerá dados sobre a capacidade estática de armazenamento, separando o Brasil em regiões, a fim de apresentar dados para investidores do ramo da agroindústria, comprovando que ainda há muitas oportunidades para negócios do ramo de armazenagem de grãos.

Assim, a partir dessa análise, pretende-se estimar se em médio prazo a capacidade de armazenagem no Brasil será compatível com a produção total de grãos ou se o país sofrerá com um déficit maior de armazenagem, visto que atualmente esse déficit já afeta muitos produtores.

\section{REFERENCIAL TEÓRICO}

Segundo Azevedo et al. (2008, p. 2) "[...] o Brasil é um dos países que mais se destaca no cenário mundial da agricultura, devido à sua crescente expansão na produção de grãos". Essa evidência ressalta a importância do país para a produção de alimentos, tanto em âmbito nacional, como em nível mundial.

Apesar da safra 2015/2016 ter sofrido com grandes períodos de estiagem e altas temperaturas, que influenciaram diretamente na produção dos produtos agrícolas, principalmente do milho, a produção

\footnotetext{
${ }^{2}$ Dados disponíveis no site da CONAB (2017) por meio do link https://www.conab.gov.br/conteudos.php?a=1252\&t=2
} 
foi de 186,6 milhões de toneladas de grãos (CONAB, 2017). Ainda, segundo o mesmo órgão, o recorde de produção foi na safra 2014/2015, com 207,7 milhões de toneladas de grãos ${ }^{3}$.

Para que esses produtos sejam utilizados posteriormente, é necessário realizar o processo de armazenagem, o qual se baseia em reunir e guardar um volume de grãos por um determinado período, a fim de que se possa preservar as características normais dos mesmos evitando fungos, pragas, umidade excessiva e entre outras (SILVA et al., 2012).

A armazenagem é feita em dois tipos tradicionais: a granel ou em volumes. Na armazenagem a granel, os grãos estão soltos em silos (metal, concreto, entre outros). Em volumes, o produto é colocado em sacos e empilhados, normalmente em galpões (AZEVEDO et al., 2008). Além desses tipos existe o silo bolsa, que consiste basicamente em, segundo Vallone (2015, p. 28), "um túnel de polietileno de alta densidade". Esse tipo de armazenamento está sendo utilizado no Brasil e no mundo, visto que o mesmo apresenta como aspecto positivo a possibilidade de ser instalado na própria área rural e assim facilitar o escoamento do produto. Porém, como fica sujeito às condições climáticas e aos predadores naturais, não pode conservar os grãos por muito tempo, necessitando assim, que após a safra, o produto seja escoado da fazenda.

Para Fernandes e Rosalem (2014), o crescimento na produção (maior do que a evolução da capacidade estática de armazenamento), aliado a um déficit histórico na relação produção/armazenagem, acaba deixando o Brasil com uma capacidade de armazenamento menor do que a sua produção atual de grãos.

Apesar de que nos últimos anos a preocupação com a capacidade estática de armazenamento tenha aumentado, e com isso, tenham sido realizados investimentos nessa área, ainda assim a capacidade de armazenagem não consegue acompanhar a evolução da agricultura, que é favorecida por muitos fatores, como o avanço da tecnologia e a expansão das áreas plantadas (LEITE, 2013). Segundo Maia et al. (2013) "[...] os estados do Sul e do Sudeste são, aparentemente, os menos afetados por problemas relacionados à armazenagem".

Embora ainda não se possa armazenar nem o que é produzido no país, segundo Gallardo et al. (2010) a Organização das Nações Unidas para Alimentação e Agricultura (FAO) recomenda que se busque uma relação de 1:1,2 entre a produção e a capacidade estática de armazenamento.

No Brasil, nem $20 \%$ dos grãos que são produzidos são armazenados nas propriedades rurais. Se comparar esse índice com o de outros grandes produtores, o país enfrenta uma imensa dificuldade. Isso porque os produtores acabam sendo prejudicados por muitas vezes perder a autonomia na hora da venda, comercializando seus produtos em períodos de safra, onde o preço normalmente é menor do que o de entressafra. Além disso, acabam sofrendo com o transporte dos grãos, pois as unidades de recebimento podem ser longe da propriedade e isso causa um problema logístico. (FERNANDES; ROSALEM, 2014)

Nesse ínterim, embasado por dados fornecidos pela CONAB (2017), serão realizadas aproximações numéricas, via Métodos dos Mínimos Quadrados, para obter uma projeção da produção e

${ }^{3}$ Dados disponíveis no site da CONAB (2017) por meio do link https://www.conab.gov.br/conteudos.php?a=1252\&t=2 
armazenagem de grãos no Brasil. Esse processo será descrito mais especificamente na próxima secção.

\section{METODOLOGIA}

Para realização deste trabalho foram coletados os dados da quantidade de grãos produzidas em anos anteriores e da capacidade de armazenagem nos respectivos anos, através do site da CONAB (2017), conforme Tabela 1.

Tabela 1 - Produção e Armazenagem no período 2000/2016

\begin{tabular}{ccc}
\hline Ano & Produção (mil t.) & Armazenagem (mil t.) \\
\hline 2000 & 83029,9 & 87833,0 \\
2001 & 100266,9 & 89227,0 \\
2002 & 96799,0 & 89734,2 \\
2003 & 123168,0 & 93358,6 \\
2004 & 119114,2 & 100056,0 \\
2005 & 114695,0 & 106538,7 \\
2006 & 122530,8 & 121987,7 \\
2007 & 131750,6 & 123401,5 \\
2008 & 144137,3 & 128484,4 \\
2009 & 135134,5 & 130780,8 \\
2010 & 149254,9 & 137828,2 \\
2011 & 162803,0 & 140456,4 \\
2012 & 166172,1 & 142482,1 \\
2013 & 188658,1 & 145485,5 \\
2014 & 193622,0 & 149506,6 \\
2015 & 207770,0 & 152355,3 \\
2016 & 186299,1 & 157624,6 \\
\hline
\end{tabular}

Fonte: adaptado de CONAB (2017).

Após a obtenção dos dados, foram realizadas aproximações através de um método numérico denominado Método dos Mínimos Quadrados, juntamente com o auxílio do software Scilab. Este método utiliza o princípio de ajustes de curvas, que tem como finalidade encontrar uma função que melhor se ajuste em uma família de dados, utilizando como critério a minimização do quadrado da diferença entre estes dados e a função. Para determinar a função que melhor descreve estes dados, segundo o coeficiente de determinação ${ }^{4}$, foram testadas as funções descritas na Tabela 2.

Tabela 2 - Equações testadas.

\begin{tabular}{ccc}
\hline Função & Equação & No \\
\hline Linear & $y=a x+b$ & $(1)$ \\
Exponencial & $y=a * e^{-b x}$ & $(2)$ \\
Potência & $y=a * x^{b}$ & $(3)$ \\
Hiperbólica I & $y=a+\frac{b}{x}$ & $(4)$ \\
Hiperbólica II & $y=\frac{1}{a x+b}$
\end{tabular}

Fonte: adaptado de Barroso (1987).

\footnotetext{
${ }^{4}$ É uma maneira de medir a qualidade do ajuste linear (ou de uma curva que foi linearizada). "Quanto mais próximo o coeficiente de determinação estiver da unidade, melhor será o ajuste" BARROSO (1987, p. 330).
} 
Após linearizarmos as equações apresentadas na Tabela 1 (exceto a equação (1) que já é linear) e aplicarmos o Método dos Mínimos Quadrados, obtivemos a curva que melhor se ajustou nos dados obtidos na CONAB (2017) e, através dessa função, foram feitas projeções de produção de grãos e da capacidade de armazenagem dos mesmos no Brasil.

\section{RESULTADOS E DISCUSSÃO}

A partir dos dados obtidos no site da CONAB (2017), utilizando os números referentes a produção e o armazenamento de grãos, do ano 2000 até o ano de 2016, utilizamos o Método dos Mínimos Quadrados implementado no Scilab para obter a equação que melhor descreve o comportamento desses dados adotando como critério o coeficiente de determinação mais próximo da unidade (BARROSO, 1987). Os resultados alcançados são apresentados na Tabela 3 (comportamento da produção) e na Tabela 4 (acerca da armazenagem de grãos).

Tabela 3 - Equações para a produção de grãos.

\begin{tabular}{ccc}
\hline Função & Equação & $\begin{array}{c}\text { Coeficiente de } \\
\text { Determinação }\end{array}$ \\
\hline Linear & $y=7050,1262 * x-14013994$ & 0,938 \\
Exponencial & $y=9,608 \times 10^{-40} * e^{0,0506359 * x}$ & 0,941 \\
Hiperbólica I & $y=14297235,61-\frac{2,84222 \times 10^{10}}{x}$ & 0,938 \\
Hiperbólica II & $y=\frac{1}{-0,000000380 * x+0,000770182}$ & 0,906 \\
\hline
\end{tabular}

Tabela 4 - Equações para a capacidade estática de armazenagem.

\begin{tabular}{ccc}
\hline Função & Equação & $\begin{array}{c}\text { Coeficiente de } \\
\text { Determinação }\end{array}$ \\
\hline Linear & $y=4730,435294 * x-9375352,86$ & 0,9689 \\
Exponencial & $y=2,23902 \times 10^{-30} * e^{0,039828170 * x}$ & 0,9489 \\
Potência & $y=7,9076 \times 10^{-260} * x^{79,98901161}$ & 0.9492 \\
Hiperbólica I & $y=9623952,828-\frac{1,90771 \times 10^{10}}{x}$ & 0,9693 \\
Hiperbólica II & $y=\frac{1}{-0,000000343 * x+0,000696479}$ & 0,9221 \\
\hline
\end{tabular}

Fonte: Autores (2017).

Após a análise das funções, foram escolhidas para a capacidade estática dos armazéns e para a produção de grãos aquelas que apresentavam o maior coeficiente de determinação, apresentadas, respectivamente na Equação (6) e na Equação (7).

$$
\begin{gathered}
y=9623952,828-\frac{1,9077 \times 10^{10}}{x} \\
y=9,608 \times 10^{-40} \sqsubset e^{0.0506359 x}
\end{gathered}
$$


A Equação (6) referente a capacidade estática de armazenagem, foi ajustada na forma de equação hiperbólica, com um coeficiente de determinação de 0,9693, que significa uma confiabilidade de 96,93\% para os pontos estimados. Para a Equação (7), o modelo utilizado foi da função exponencial, onde foi encontrado um coeficiente de determinação de 0,941, ou seja, 94,1\% confiável.

Com as equações definidas, foram estimadas as projeções de produção e armazenagem para o período de 2017-2021, os quais estão ilustrados na Figura 1.

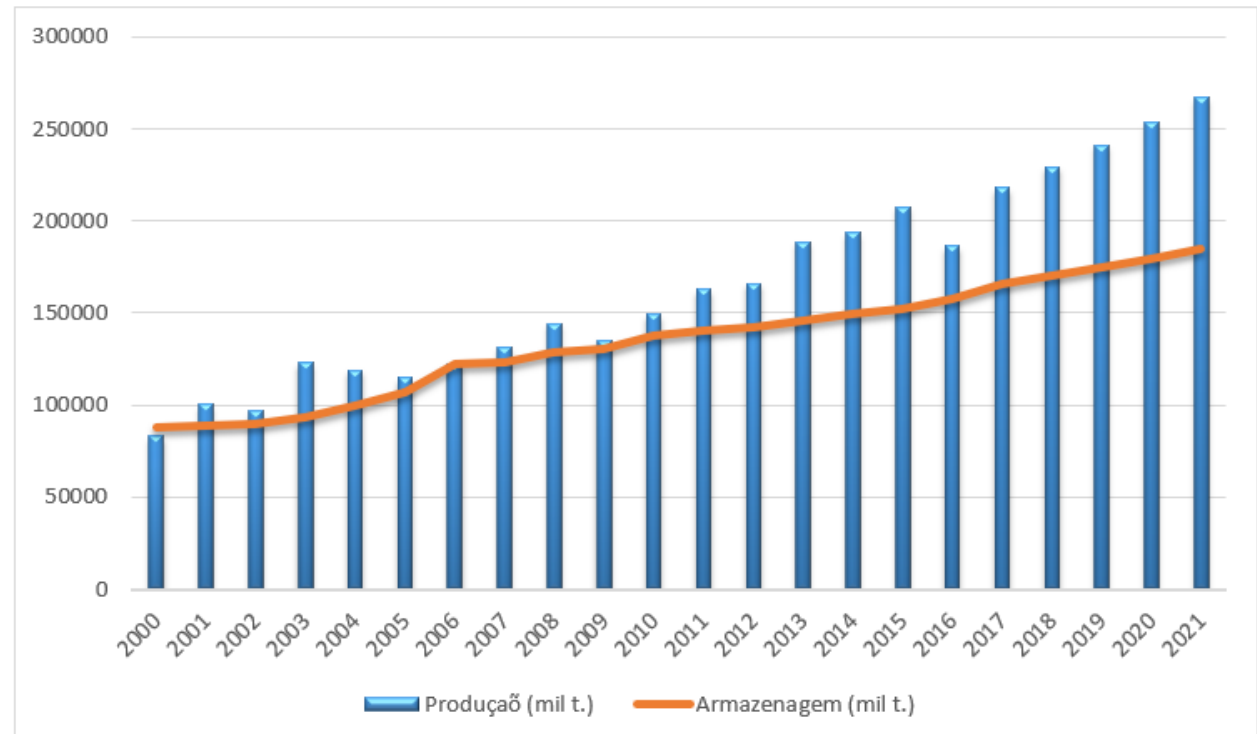

Figura 1 - Produção e armazenagem período 2000/2021.

Fonte: Dados obtidos no site da CONAB até 2016 e projeção obtida pelas equações (6) para armazenagem estática e (7) para produção de grãos.

Analisando a Figura 1, pode-se constatar que a armazenagem na grande maioria dos anos, foi inferior a produção, principalmente nos últimos anos, concordando com a ideia de Fernandes e Rosalem (2014), de que o Brasil não consegue estocar toda a sua produção atual de grãos, devido à falta de capacidade estática de armazenamento.

A Figura 2 corrobora a afirmação anterior, pois ilustra a área plantada, produção e armazenagem de grãos no período de 1990/2016.

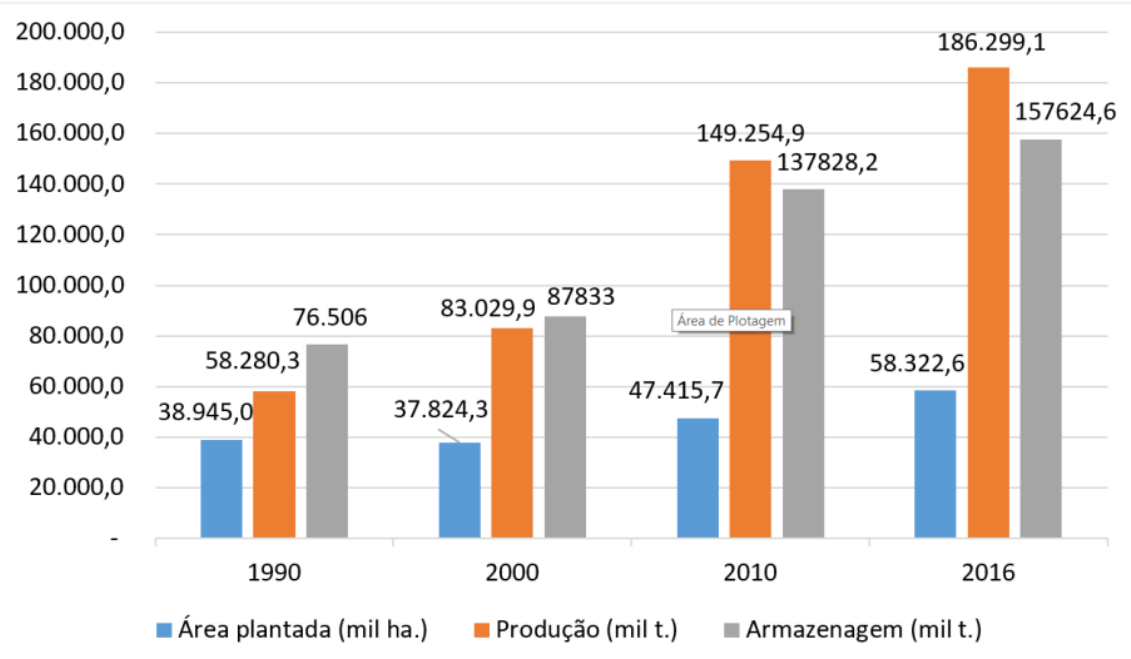

Figura 2 - Área plantada, produção e armazenagem no período 1990/2016.

Fonte: adaptado de CONAB (2017). 
A partir dos dados das Figuras 1 e 2, observa-se que até o ano 2000 não havia déficit de armazenagem. No período 1990-2000, segundo os dados da CONAB (2017), a área plantada mantevese nos mesmos patamares, porém, houve apenas o crescimento da produção e, no mesmo tempo, a capacidade estática de armazenagem.

Nos anos de 2000-2010, nota-se que houve um aumento gradativo da produtividade por hectare e da área plantada (Tabela 5). Isso gerou um incremento da produção que, por sua vez, causou um déficit de armazenagem. Fica claro que esse aumento de produtividade, além da expansão das lavouras, se deve principalmente pelo grande sucesso do uso de tecnologias na agricultura brasileira após o ano 2000.

Tabela 5 - Produtividade e área plantada no período 2000/2016.

\begin{tabular}{lcc}
\hline Ano & Produtividade (kg/ha) & Área Plantada (mil ha.) \\
2000 & 2195 & $37.824,3$ \\
2001 & 2649 & $37.847,3$ \\
2002 & 2407 & $40.235,0$ \\
2003 & 2803 & $43.946,8$ \\
2004 & 2512 & $47.422,5$ \\
2005 & 2339 & $49.068,2$ \\
2006 & 2560 & $47.867,6$ \\
2007 & 2851 & $46.212,6$ \\
2008 & 3040 & $47.411,2$ \\
2009 & 2835 & $47.674,4$ \\
2010 & 3148 & $47.415,7$ \\
2011 & 3264 & $49.872,6$ \\
2012 & 3266 & $50.885,2$ \\
2013 & 3522 & $53.563,0$ \\
2014 & 3393 & $57.059,9$ \\
2015 & 3588 & 57914,7 \\
2016 & 3199 & $58.336,0$ \\
\hline
\end{tabular}

Fonte: adaptado de CONAB (2017).

Para o período 2010-2016, de acordo com a Tabela 5, a produtividade por hectare desenvolveu-se de maneira quase contínua juntamente com a ampliação da capacidade estática de armazenagem. A produção, por sua vez, alavancou, sendo explicada pelo fato de que a área cultivada aumentou quase o dobro nesse período, com média de 1817,82 mil hectares por ano, se comparado com o período 2000-2010, que conseguiu uma média de 959,14 mil hectares por ano, fazendo assim com que houvesse um crescimento do déficit de armazenagem.

Baseado na Equação (6) e na Equação (7) foram realizadas as estimativas de produção e capacidade estática de armazenamento, para o período 2017-2021, possibilitando assim a obtenção dos dados para a construção da Tabela 6. 
Tabela 6 - Estimativa para a produção x Capacidade estática de armazenagem no período 2017-2021.

\begin{tabular}{ccccc}
\hline Ano & $\begin{array}{c}\text { Produção } \\
\text { (mil t.) }\end{array}$ & $\begin{array}{c}\text { Capacidade Estática } \\
\text { (mil t.) }\end{array}$ & $\begin{array}{c}\text { Diferença } \\
\text { (mil t.) }\end{array}$ & $\begin{array}{c}\text { Déficit } \\
\text { (em \%) }\end{array}$ \\
\hline 2017 & 217918,2 & 165809,8 & $-52108,4$ & $-23,91$ \\
2018 & 229236,9 & 170496,7 & $-57611,3$ & $-25,62$ \\
2019 & 241143,4 & 175178,0 & $-64749,4$ & $-27,36$ \\
2020 & 253668,4 & 179856,6 & $-73811,8$ & $-29,10$ \\
2021 & 266843,9 & 184529,6 & $-80927,3$ & $-30,85$ \\
\hline
\end{tabular}

Fonte: Autores (2017).

Na Tabela 6, as estimativas apontam para um crescimento maior da produção em relação a capacidade estática nos próximos anos, sendo assim, exibe uma grande tendência de aumento do déficit de armazenagem para as próximas safras. Esse fato requer uma atenção tanto do governo, que precisa se preocupar com o alimento, quanto do agricultor, que deseja viabilizar cada vez mais o seu negócio, que se baseia na comercialização, com maior lucro, dos grãos produzidos por ele.

Os dados de capacidade estática e de produção fornecidos pela CONAB (2017) são contabilizados por estado, região e o somatório do país, os quais se referem à Safra 2015/16 e estão apresentados na Tabela 7.

Tabela 7 - Produção X Capacidade Estática na Safra 2015/16.

\begin{tabular}{lcccc}
\hline \multicolumn{1}{c}{ Região } & Produção (mil t.) & Capacidade Estática (mil t.) & Diferença (mil t.) & Déficit (em \%) \\
\hline Norte & 6936,6 & 4051,9 & $-2884,7$ & $-41,59$ \\
Nordeste & 9973,4 & 10372,8 & $+399,4$ & $+4,00$ \\
Centro-Oeste & 75293,1 & 57698,6 & $-17594,5$ & $-23,37$ \\
Sudeste & 19467,0 & 23500,7 & $+4033,7$ & $+20,72$ \\
Sul & 74629,0 & 66450,6 & $-8178,4$ & $-10,96$ \\
\multicolumn{1}{c}{ Total } & 186299,1 & 162074,6 & $-24224,5$ & $-13,00$ \\
\hline
\end{tabular}

Fonte: adaptado de CONAB (2017).

Com base na Tabela 7, fica evidente que, nas regiões Norte, Centro-Oeste e Sul, há déficit de armazenagem devido à alta produção de grãos, principalmente, no Centro-Oeste e no Sul, por já serem regiões consolidadas na agricultura. No Norte, o déficit se dá devido ao crescimento elevado da produção das últimas safras, visto que essa região é considerada uma nova fronteira agrícola do país, com destaque para a produção de soja e milho, que segundo dados da CONAB (2017), obtiveram um crescimento de $23 \%$ na safra 2014/15.

Nas regiões Sudeste e Nordeste, a produção foi menor que a capacidade estática de armazenagem. Analisando os dados dos anos anteriores podemos perceber que, no Nordeste, isso ocorreu pelo fato de que a produção decresceu muito em relação as safras anteriores. Segundo os dados da CONAB (2017), na safra 2014/15, na região Nordeste, a produção foi de 16586,6 mil toneladas enquanto a capacidade estática era de 9804,4 mil toneladas, evidenciando que a diferença para mais da capacidade de armazenagem em relação à produção foi pelo fato de que ocorreram problemas na produção de grãos. Analisando as regiões produtoras brasileiras, o Sudeste é a única em que a capacidade estática é excedente e consolidada, visto que o Nordeste apresentou somente nesta safra um saldo de armazenagem, seguidos pelo Sul, em que há o menor déficit do país, cerca de $11 \%$. Isso 
corrobora a ideia de Maia et al (2013), de que os estados do Sul e Sudeste são menos prejudicados em relação a armazenagem de grãos.

A partir das Tabelas 6 e 7, foi verificado que as regiões que mais carecem de investimento na armazenagem de grãos são as regiões Norte seguida da Centro-Oeste, com déficit de 41,59\% e $23,37 \%$, respectivamente. No Norte, o principal fator que um investidor deve levar em consideração é de que a produção cresceu muito nas últimas safras e deve crescer mais, pelo fato de que a região está sendo considerada uma nova fronteira agrícola do país, ou seja, ela está sendo cada vez mais explorada. Já no Centro-Oeste, maior produtora de grãos do Brasil, o principal argumento para o investimento é de que a região é consolidada na agricultura, sendo que a cada safra vem aumentando significativamente a sua produção e área cultivada.

\section{CONSIDERAÇÕES FINAIS}

Os apontamentos realizados nessa pesquisa induzem a conclusão de que o crescimento expressivo da produção ocorreu, principalmente, devido ao aumento significativo da área cultivada, juntamente, com a tecnologia, que nos últimos anos teve uma grande evolução na área agrícola, resultado da ajuda financeira que o país concedeu aos produtores através de financiamentos com juros baixos, tanto para a modernização dos equipamentos usados para o cultivo das lavouras quanto para o custeio das mesmas.

O fato de o país ter se tornado uma grande potência quando se trata de produção de grãos, trouxe à tona a preocupação com o armazenamento desses produtos. Além de cultivar com excelência, se faz necessário o investimento em armazenagem, tanto nas fazendas quanto em depósitos terceirizados. Algumas medidas já foram tomadas para que a situação da capacidade estática possa ficar semelhante à produção de grãos, como a criação de uma linha de crédito para construção de silos em propriedades rurais e empresas do ramo de armazenagem, porém o crescimento da produção ainda é superior ao da capacidade estática.

Com base nos dados fornecidos pela CONAB (2017), e através das equações obtidas, foi possível realizar as estimativas de produção e armazenagem dos próximos anos. Com isso, a conclusão foi de que o Brasil sofrerá de um déficit de armazenagem muito elevado no futuro, caso não sejam tomadas medidas compatíveis com a deficiência da capacidade estática do país. Apesar da Equação (6) ter sido obtida com $97 \%$ de confiabilidade nos dados estimados pela curva da produção de grãos, é importante ressaltar que a equação não leva em conta fatores climáticos, desastres naturais, e outros fatores que possam acarretar em uma queda brusca da produção.

O Brasil, considerado um dos principais produtores de grãos em escala mundial e com grande tendência de aumento em sua produtividade, tem grandes opções para investidores no mercado da armazenagem de grãos, visto que a carência por capacidade estática está presente no pais e os dados apontam para o aumento desse déficit. Com os dados de produção e armazenagem, foi possível esboçar, separando em macrorregiões, os respectivos números, mostrando assim que existem várias regiões do Brasil que são opções que já possuem demanda para armazenadores de grãos, sendo assim consideradas ótimas opções para investidores. 


\section{REFERÊNCIAS}

AZEVEDO, Loianny Faria et al. A capacidade estática de armazenamento de grãos no brasil, Rio de Janeiro, outubro de 2008. Disponível em: <http://abepro.org.br/biblioteca/enegep2008_TN_STP_069_492_11589.pdf>. Acesso em 22 de jan. 2017.

BARROSO, Leônidas C et al. Cálculo Numérico com aplicações. 2. ed. São Paulo: Editora HARBRA, 1987. 367p.

CHAPRA, Steven C.; CANALE, Raymond P. Métodos Numéricos para Engenharia. 5. ed. São Paulo: McGraw-Hill, 2008. 832p.

Companhia Nacional de Abastecimento - CONAB. Disponível em: < http://www.conab.gov.br/>. Acesso em 26 de jan. 2017.

Empresa Brasileira de Pesquisa Agropecuária - EMBRAPA. Disponível em:< https://www.embrapa.br/soja/cultivos/soja1>. Acesso em 12 de fev. 2017.

FERNANDES, Queli S.; ROSALEM, Vagner. O cenário da armazenagem no brasil, novembro de 2014. Disponível em: <http://www.conhecer.org.br/enciclop/seminario/O\%20cenario.pdf>. Acesso em 22 de jan. 2017.

GALLARDO, Alfonso Pires et al. Avaliação da capacidade da infra-estrutura de armazenagem para os granéis agrícolas produzidos no Centro-Oeste brasileiro. São Paulo: POLI, USP, 2010. Disponível em: <http://docplayer.com.br/990317-Avaliacao-da-capacidade-da-infra-estrutura-dearmazenagem-para-os-graneis-agricolas-produzidos-no-centro-oeste-brasileiro.html>. Acesso em 10 de jan. 2017.

LEITE, Guilherme Leão. Capacidade de armazenamento e escoamento de grãos do estado do mato grosso, Brasília, março de 2013. Disponível em: <http://bdm.unb.br/bitstream/10483/4739/1/2013_GuilhermeLe\%C3\%A3oDiasLeite.pdf>. Acesso em 11 de fev. 2017.

MAIA, Guilherme Baptista da Silv. et al. Panorama da armazenagem de produtos agrícolas no Brasil. Revista do BNDES, n. 40, p. 161-194, dezembro de 2013. Disponível em: <http://www.bndes.gov.br/SiteBNDES/export/sites/default/bndespt/Galerias/Arquivos/conhecimento /revista/rev4005.pdf>. Acesso em 14 de fev. 2017.

SILVA, Angélica Leme da. et al. Um estudo acerca da capacidade de armazenagem de grãos no município de Palmital-SP, Palmital, 2012. Disponível em: <http://www.etecpalmital.com.br/_biblioteca/_tcc/_logistica/_2012/_arquivos/UMESTUDOACERCAD ACAPACIDADEDEARMAZENAGEMDEGRAOSNOMUNICIPIODEPALMITAL.pdf>. Acesso em 5 de fev. 2017.

VALLONE, Bruno Antoniazzi. Utilização de silo bolsa no armazenamento de milho, Curitiba, $2015 . \quad$ Disponível em:

http://acervodigital.ufpr.br/bitstream/handle/1884/42272/R\%20-\%20E\%20-\%20BRUNO\%20ANTON IAZZI\%20VALLONE.pdf?sequence=1>. Acesso em 08 de jun. 2017. 